\title{
Assessment of Entrepreneurship and Innovation in Newcoming Romanian Entrepreurial Universities
}

\author{
Carmen Eugenia NASTASE \\ "Ștefan cel Mare” University, Suceava, Romania \\ carmenn@seap.usv.ro \\ Alina-Ramona BUTNARIU \\ "Ștefan cel Mare" University, Suceava, Romania \\ alinaramonabutnariu@gmail.com \\ Ancuța LUCACI \\ "Ștefan cel Mare" University, Suceava, Romania \\ ancutalucaci28@yahoo.com
}

\begin{abstract}
In the dynamic changing environment, entrepreneurial universities have been playing an increasingly important role for socio-economic innovation and development. The aim of this study is to perform an analysis, involving the observation of the dimensions of entrepreneurial universities. We consider that nowadays the evaluation of universities should take into consideration the tools that school leaders, professors and students may use to evaluate teaching programs in innovation and entrepreneurship. As a result of the fact that the tertiary education institutions are appreciated by the way they relate to the social and economic needs and characteristics of the individuals, the Romanian universities are currently pursuing and trying to undergo a development process making the shift from a classical university to an entrepreneurial university. Specific literature has argued that the dynamic culture of the entrepreneurial university encourage students and graduates to new innovative and entrepreneurial initiatives and increase their employability. The purpose of the current paper is to inspire debates and actual steps to be taken so as higher education institutions in Romania to become even more competitive and support economic growth by fully embracing the role of entrepreneurial universities. Research methodology includes the application of the questionnaire conceived by the HEInnovate team in two universities from Romania, authors comparing the results through a qualitative analysis and interpretation within the European framework. Results underline a similarity between the responses among the seven pillars of HEInnovate tool, but given the area of influence we identify the gaps and propose specific recommendations for short and long-term future. The conclusions of paper area meant to enhance performance in development of innovation and entrepreneurial skills in students in North-East region of Romania, with the aim to raise the region's competitive edge.
\end{abstract}

Keywords: innovation, entrepreneurship, entrepreneurial university, knowledge society, tertiary education, educational strategy

\section{Introduction}

The challenges of the $21^{\text {st }}$ century are to be found on multiple levels for humankind: societal, economical and on individual level. From social inequalities to handling the minorities and immigrants, from eradication of world poverty to climate change and managing its costs, from intrusions in personal data to fulfilling new employment requirements, these are only a few issues to be addressed, but at the same time they are 
opportunities to further development of civilization by discovery and re-discovery of our potential. A vital role in this process has to be acknowledged that of the expanding role of technology and innovation as drivers to sustainability. With more governments facing political crisis and exponential increase in public expenses, entrepreneurship seems to be one of the solutions to support fill in the gap of social disruption. In order to face the complex problems which already exist and might even occur in the near future, education has to keep up with the progress by delivering competitive results and prepare skillful individuals.

It is undoubtedly a period of deep transformation that we are going through since business activities have reached globalization and knowledge has become the main asset in organizations (Dunning, 2002). In fact, this is the root of our current endeavor, which Drucker expressed it in such an elegant manner: "the knowledge society must have at its core the concept of the educated person" (Drucker, 2001). It is now more obvious than ever that business require complex skills, such as expert thinking and complex communication skills (Levy \& Murnane, 2005) as machinery and equipments took over the real persons work. It is no later than today the perfect time to question ourselves if education is ready to prepare learners to face globalization and become conscious and active citizens, ready to face challenges with a society mainly mobile and IT-dominated, competent workers in any field and, above all, equipped with the skills appropriate to both our level of development and the society's needs. Thus, the researchers in the field of education have promoted the need for changes and adjustments in the educations systems to better support the development of skills required in the new knowledge society, as an evolution from information society (UNESCO, 2003).

Knowledge alone seems not to be enough in order to prepare learners to respond to societal needs. Thus educational systems all over the world are being put into the position of renewing themselves since employers are increasingly speaking lately of hiring newly graduates with no skills to be used in the workplace. There are scholars that have stated that whenever knowledge is acquired in a passive manner, with no skills, is only learned at a superficial level, mostly insufficiently on the whole. In this case, we might view knowledge as being "troublesome", which is, tacit, inert, and ritual or even alien (Perkins, 1999). This kind of knowledge is not thus easily transferred into the real world environments, into the working environments. Only by combining and balancing skills learning with knowledge domains could learners acquire abilities such as pro-action and deep understanding or, as studies have shown, that "educators and policymakers must ensure that content is not shortchanged for an ephemeral pursuit of skills. Skills and knowledge are intertwined." (Rotherham \& Willingham, 2009)

Although entrepreneurship curricula and educational programs are available for learners at tertiary level of education, little has been assessed regarding the efficient use of the knowledge acquired, let alone the further intentions of learners' for innovative business development.

The basic assumption of the current study is that entrepreneurship and innovation can be learned and consequently they should be taught with the support of appropriate educational environment, and thus we are focused on the importance of delivering relevant educational outcomes in what concerns teaching entrepreneurial and innovation skills to youths. We are hence preoccupied in the present paper with discussing the concept of 
entrepreneurial university and one of the tools at hand nowadays to assess entrepreneurship and innovation culture in higher education institutions (HEIs). We consider the self-assessment tool represented by the HEInnovate questionnaire as being systematic enough to start debating on the current state of play in universities in Romania with regards to entrepreneurship and innovation. Finally, some recommendations are being formulated to enhance and improve the systemic efforts with regards to improving entrepreneurial and innovative dimensions of universities in their endeavors to make the transformation from exclusively learning institutions to entrepreneurial universities, in accordance with international strategies and policies in the field.

\section{Literature review}

\section{Entrepreneurship and innovation}

Essentially, entrepreneurship is considered to be the act of developing a new business and, as a process, leads to innovation and growth (Wilson, Vyakarnam, Volkmann, Mariotti, \& Rabuzzi, 2009). The trademark of an entrepreneurial initiative is its ability to innovate and assume risks, taking advantage of that "windows of opportunity" since innovation and entrepreneurship are intertwined at organizational level and Drucker (2008) was among the scholars to observe and comment upon this connection. As overlapping concepts, one of the first definitions track back to Schumpeter (Croitoru, 2012) who defines the entrepreneur as an individual achieving new mixtures or combinations (i.e. innovations). Schumpeter identifies four distinct roles in the process of innovation, that is: the inventor as the individual who invents the new idea, the entrepreneur as the one who commercialize the new idea, the capitalist as the provider of financial resources to the entrepreneur and last, the manager, as the one who tends to the daily corporate management routine.

It is no doubt that entrepreneurship is viewed as a complex phenomenon and the great amount of definitions substantiate this (Hebert \& Link, 1989). Since we do not aim at establishing which one of these is the most accurate, we prefer to assert that the concept is being studied and researched under multiple dimensions, with a view over its abundance of roles and functions. Entrepreneurship is thus defined as the pursuance of opportunities, with no regard to the resources under control at a certain point (Stevenson and Jarillo, 1990) or as a choice of occupational nature to work and risk for oneself (Stephan \& Uhlaner, 2010). An interesting view on entrepreneurship is offered by Lee, Peng, \& Song (2013) who suggest that the concept may be described as "a specific effort by an existing firm or new entrant to introduce a new combination of resources".

Trying to offer a perspective on the concept of entrepreneurship, Davidsson (2004) takes a series of definitions and distinguishes two phenomenona that are characteristic to entrepreneurship. The first one relates to the fact that some individuals prefer working for themselves rather being employed. To achieve in this way or, better said, to survive, takes some degree of innovativeness, but this is not the main focus of the process as he introduces the term "independent business". The second phenomenon includes the development and renewal of any given society, market, economy or even organization, which is based on micro-level actors with initiative and perseverance to make changes happen. In the context of this paper, we focus on the meaning of this second phenomenon seen more as an activity closely related to innovation. We argue that the change targeted in 
the market brings about value for users or consumers, which is or at least should be a desirable objective for any entrepreneurial initiative.

With regards to the concept of innovation, this is about the development of new knowledge added to the economy in such a way that it drives to economic growth and over time there were formulated multiple arguments that sustain this (see for example Westwood \& Low, 2003). In this particular instance, innovation is being valued not only for individual reasons and organizational performance, but also for economic success that it leads to and social development on a worldwide level. This global extent of the concept entails more than one stakeholder and in this line of thought, innovation has been defined as the development of either the product or practice of new and beneficial ideas for a number of interested factors such as individuals, teams of people, organizations or a wider range of society (Bledow, Frese, Anderson, Erez, \& Farr, 2009). Similarly, Noteboom and Went (2008) recognized that innovation means also the cognition of the involved actors in the process and this cognition develops from interactions of practices.

When comparing the two concepts, entrepreneurship and innovation, we might conclude that they are not self-sufficient; they oftentimes take into consideration the context and lead to change the internal environment, as well as the external one. Whether the change is beneficial or not, this is an issue depending on policies, opportunities and harmonization of needs with measures taken and achieved results. We argue that both entrepreneurship and innovation are a continuous process and evolve from past knowledge into future vision of endless improving individuals, organizations, processes.

\section{Entrepreneurial university}

The entrepreneurial University is often characterized by the university's ability to respond proactively and positively to a changing, uncertain and increasingly complex environment, and to innovation (Gibb et al., 2012).

Since change and complex transformation affect so many aspects of the world today, universities are not left behind and along with internalization, redefining teaching skills for $21^{\text {st }}$ century and even financial restrictions, they are forced to take in more relevant roles which go beyond the two main activities of higher education institutions (HEI), research and teaching (Etzkowitz, 2004). In other words, tertiary education institutions make use of knowledge by teaching it to learners, transferring it to the economy through students, future employees or researching it, publishing relevant information in scientific journals. Such transfer of knowledge is characteristic to traditional universities while entrepreneurial university redefines these traditional roles of HEI in the community as a creator of knowledge through basic and applied research, technology and knowledge transfer promoter, innovator, and, last but not least, supporter of economic growth (Bercovitz \& Feldmann, 2006). The model described by Bercovitz and Feldman recognizes the role of universities in the study of innovation, as knowledge based system, since they are not only creating knowledge, but also deploying it to economically useful purposes.

When making such a transformation, new activities are to be assumed and they are aimed at speeding up the process of commercializing that rise from research and this is more than a timely practice; it may be used to redefine a university strategy and should be used to consolidate efforts in what concerns entrepreneurship (Clark, 1998). 
The challenges of this transformative process from traditional to entrepreneurial universities include even the worst "unfavorable circumstances", but even this or "being peripheral and with no advanced economy nearby is not a good excuse to justify inaction, no engagement for local economic development or poor quality of research". With this in mind, there is no doubt that entrepreneurial university will definitely play a vital role in advancing the global knowledge-based economy (Lazzeretti \& Tavoletti, 2005). At a first glance, the unfavorable circumstances taken into consideration in the present paper when debating the cases of newcoming entrepreneurial universities in Romania are, among others, resistance among leadership of some HEIs or lack of public support or national strategies or policies.

Going deeper in analyzing the entrepreneurial university, Salamzadeh et al. (2011) elaborate on its elements and develop a framework by which "an entrepreneurial university is a dynamic system, which includes special inputs (Resources, Culture, Rules and regulations, Structure, Mission, Entrepreneurial capabilities, and Expectations of the society, industry, government and market.), processes (Teaching, Research, Managerial processes, Logistical processes, Commercialization, Selection, Funding and financial processes, Networking, Multilateral interaction, and Innovation, research and development activities), outputs (Entrepreneur human resources, Effective researches in line with the market needs, Innovations and inventions, Entrepreneurial networks, and Entrepreneurial centers) and aims to mobilize all of its resources, abilities and capabilities in order to fulfill its "Third Mission". We concur to this definition since it relates to the university as system that is no longer left alone, at the outskirts of economic system, with no ties nor common grounds to the new economy, but integrative part of it, and by redefining their roles and mission, they actively contribute to socio-economical development of society.

\section{Methodology}

In this paper authors approached both quantitative and qualitative research methods. The quantitative approach was achieved through the investigation, using as a tool the questionnaire conceived by HEInnovate team. Also, qualitative analysis was used, more exactly the comparative analysis and interpretation of the questionnaire results with regards to the entrepreneurship and innovation dimensions of two universities in Romania. The questionnaires were filled online by the stakeholders of the higher education institutions.

The questionnaire was carried out to the stakeholders of two universities from Romania: "Ștefan cel Mare" University of Suceava (USV) and Politehnica University of Timișoara (UPT). Within "Ștefan cel Mare" University of Suceava, 175 of respondents filled the HEI questionnaire, while at Politehnica University of Timișoara (UPT), the case study was carried out to a sample of 400 people, during the year 2017 (Taucean, Strauti, \& Tion, 2018).

At "Ștefan cel Mare" University of Suceava, the respondents that filled the HEI questionnaire were 108 students, 26 non-students (professors, Dean, Rectorate, experts, researchers, PhD, Post Doctoral, IT\&C, administrative, others) and 41 anonymous. Only selfassessments where respondents filled out responses to affirmations related to at least one of the seven pillars of self-evaluation were considered. Within Politehnica University of 
Timișoara, the respondents were 267 students, 53 non-students (professors, deans, $\mathrm{PhD}$ students, administrative personnel, researchers) and 80 anonymous people.

The questionnaire that was applied in the two universities from Suceava and Timissoara, was conceived by HEInnovate team and is based on seven pillars. HEInnovate is a self-assessment tool for tertiary education institutions, which enables them to mark and develop their skills as entrepreneurial universities, by capitalizing on their entrepreneurial and innovative potential. It is worth mentioning that this tool is meant to offer HEIs some ideas in order to improve their management on their pathway to becoming entrepreneurial universities, being applicable to all types and sizes of universities.

Regarding the other research method, the qualitative analysis, we used the comparative analysis to interpret, explain and highlight the similarities and differences between the results obtained through the HEI questionnaire, within the European framework.

\section{Results and discussions}

Below there are graphically represented the results of the questionnaire for all seven areas: Leadership and governance; Organizational capacity: funding, people and incentives; Entrepreneurial teaching and learning; Preparing and supporting entrepreneurs; Knowledge exchange and collaboration; The internationalized institution and Measuring impact. The results for "STtefan cel Mare” University are presented in figures 1 to 7 and the results for Politehnica University of Timișoara are presented in figures 7 to 14 .

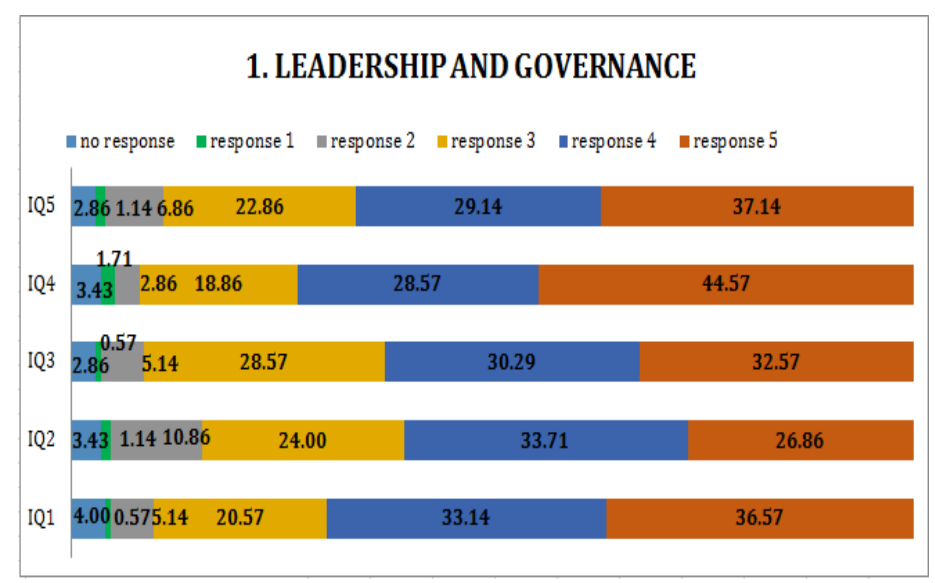

Figure 1. „Ștefan cel Mare” University of Suceava - Survey results for Area 1

Source: Authors' own research

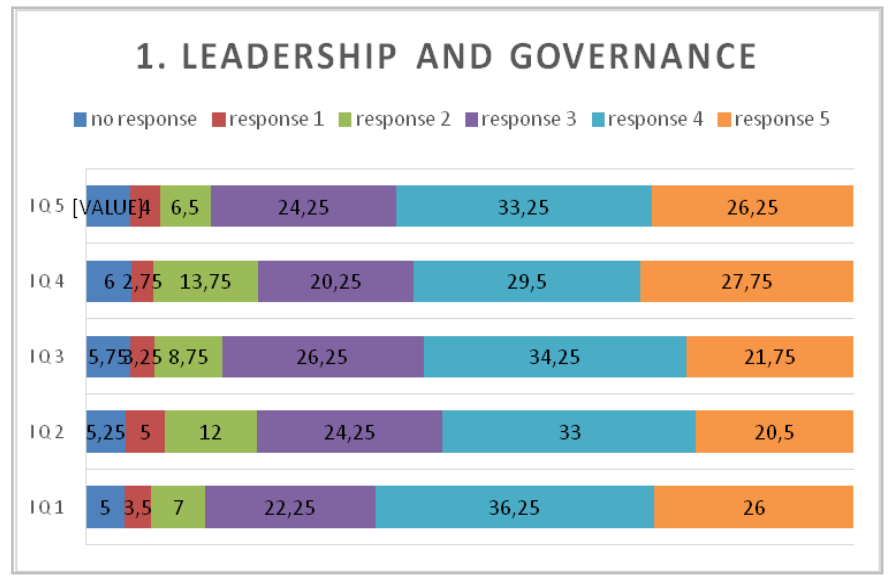

Figure 8. Politehnica University of Timișoara Survey results for Area 1

Source: Taucean, I. M., Strauti, A. G., Tion, M., Roadmap to Entrepreneurial University - Case study, Elsevier Ltd., 2017 


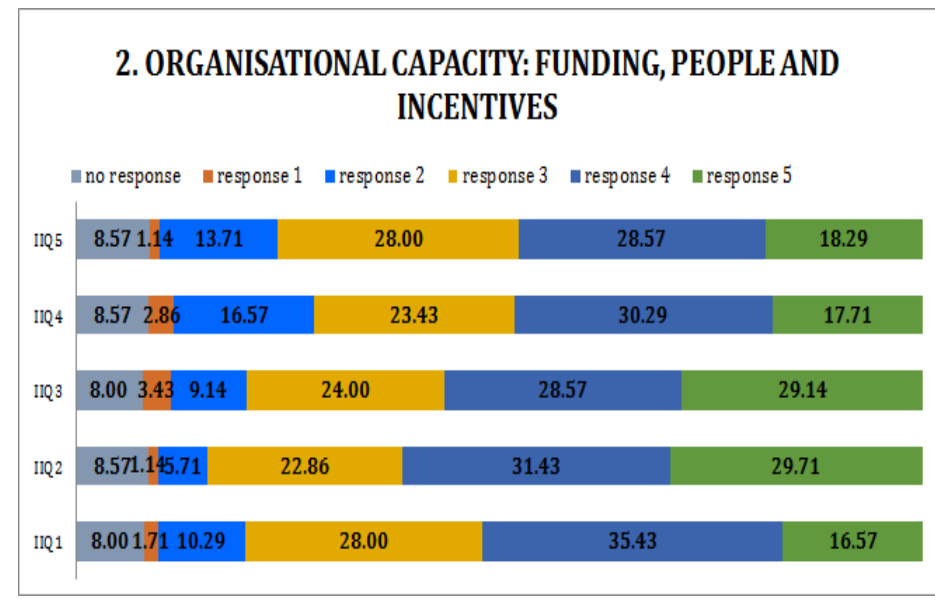

Figure 2. „Ștefan cel Mare" University of Suceava Survey results for Area 2

Source: Authors' own research

\section{ENTREPRENEURIALTEACHING AND LEARNING}

॥no response $\|$ response 1 response 2 |response 3 |response 4 response 5

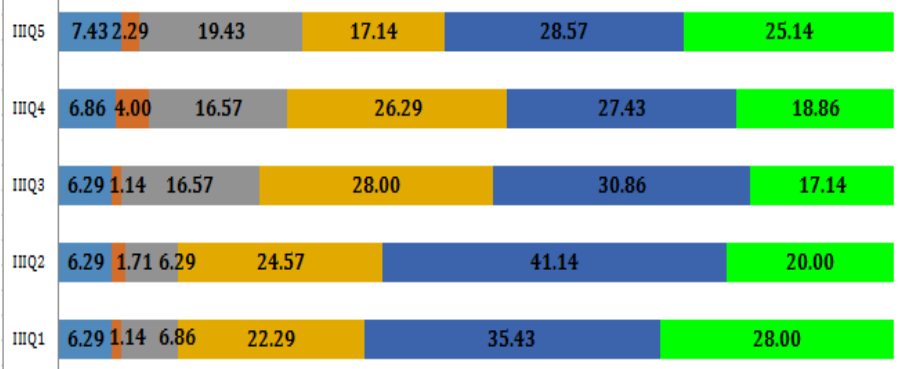

Figure 3. „Ștefan cel Mare” University of SuceavaSurvey results for Area 3

Source: Authors' own research

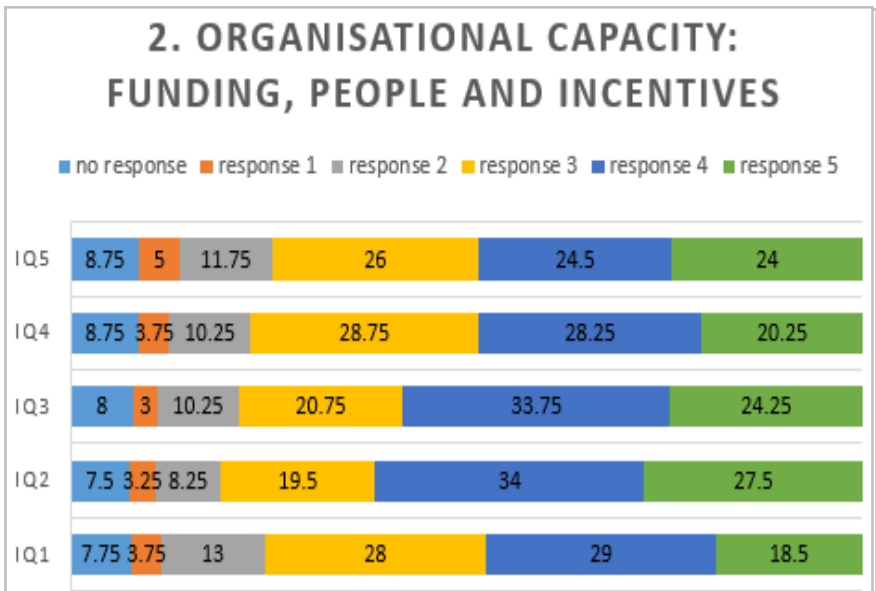

Figure 9. Politehnica University of Timișoara Survey results for Area 2

Source: Taucean, I. M., Strauti, A. G., Tion, M., Roadmap to Entrepreneurial University - Case study, Elsevier Ltd., 2017

\section{ENTREPRENEURIAL TEACHING AND LEARNING}

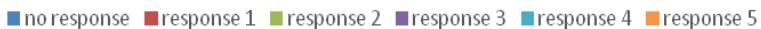

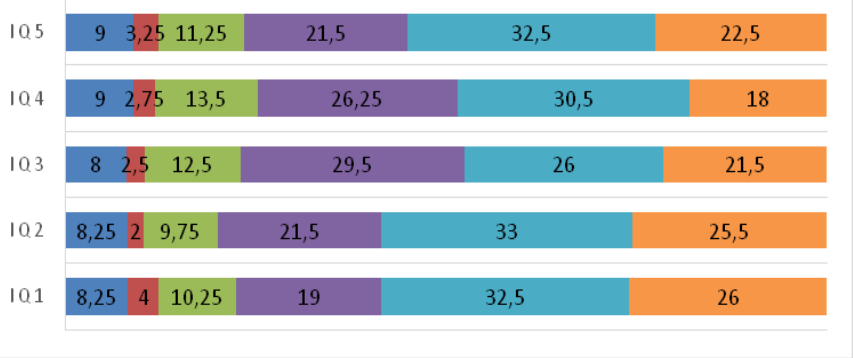

Figure 10. Politehnica University of Timișoara Survey results for Area 3

Source: Taucean, I. M., Strauti, A. G., Tion, M., Roadmap to Entrepreneurial University - Case study, Elsevier Ltd., 2017 


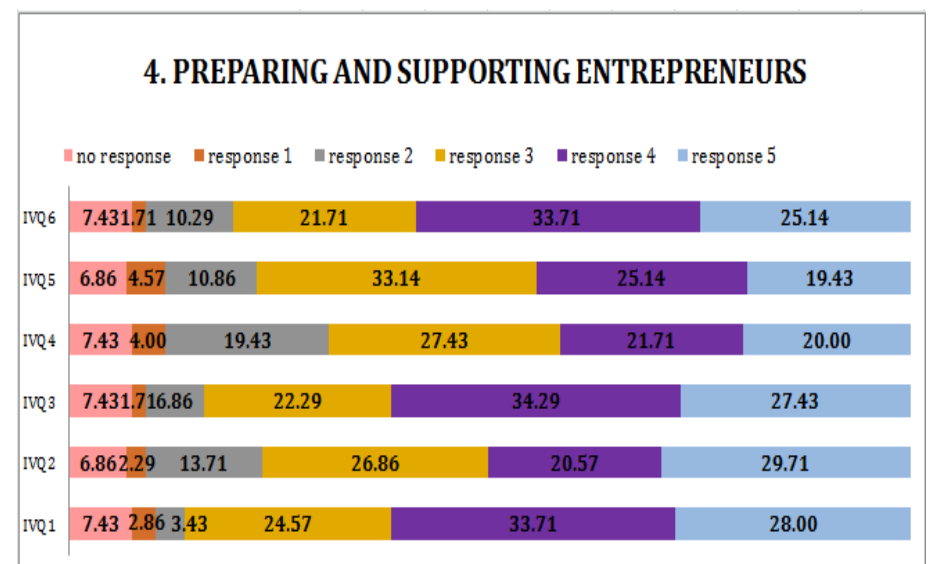

Figure 4. „Ștefan cel Mare” University of SuceavaSurvey results for Area 4

Source: Authors' own research

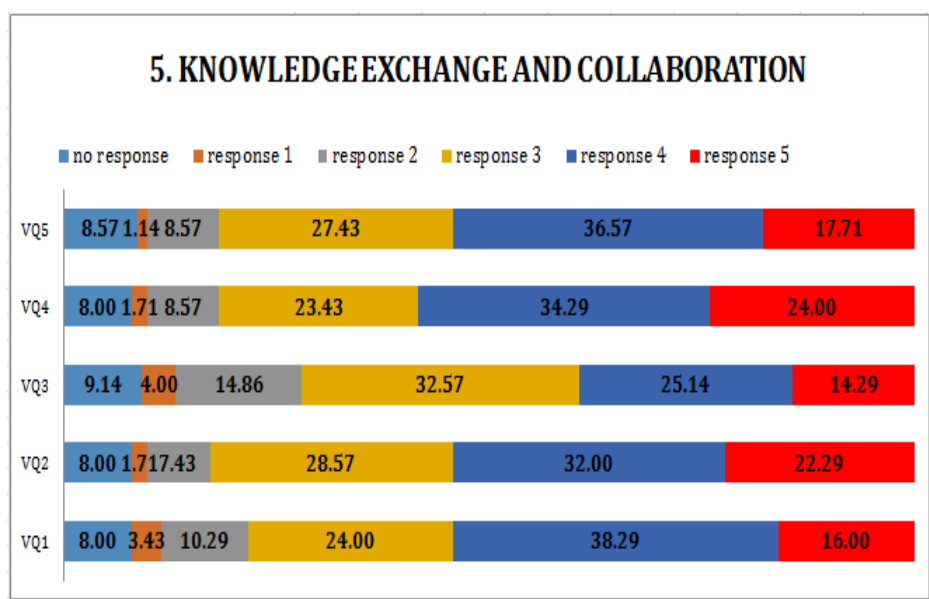

Figure 5. „SStefan cel Mare” University of SuceavaSurvey results for Area 5

Source: Authors' own research

\section{PREPARING AND SUPPORTING ENTREPRENEURS}

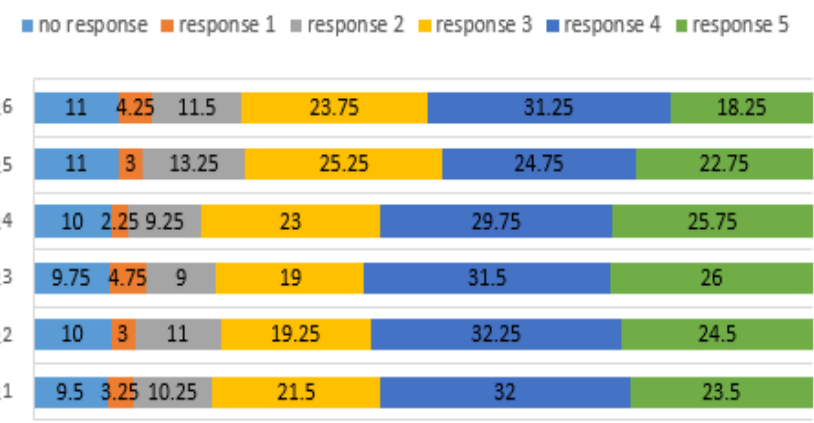

Figure 11. Politehnica University of Timișoara Survey results for Area 4

Source: Taucean, I. M., Strauti, A. G., Tion, M., Roadmap to

Entrepreneurial University - Case study, Elsevier Ltd.,

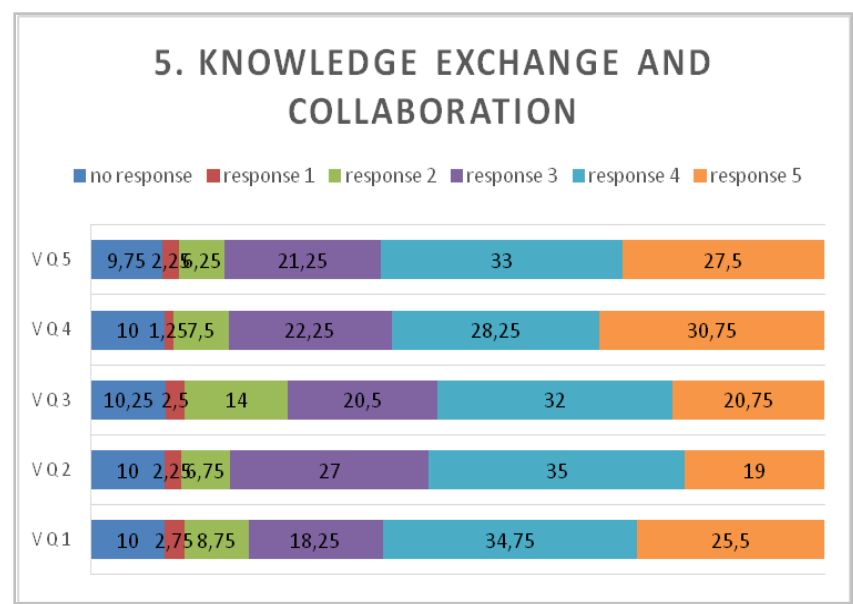

Figure 12. Politehnica University of Timișoara Survey results for Area 5

Source: Taucean, I. M., Strauti, A. G., Tion, M., Roadmap to Entrepreneurial University - Case study, Elsevier Ltd., 2017 


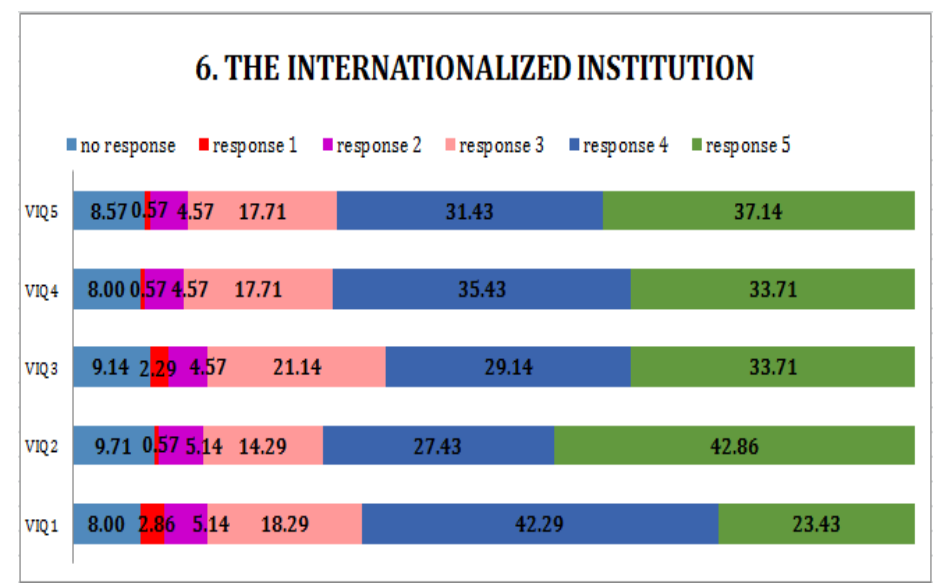

Figure 6. „Ștefan cel Mare” University of SuceavaSurvey results for Area 6

Source: Authors' own research

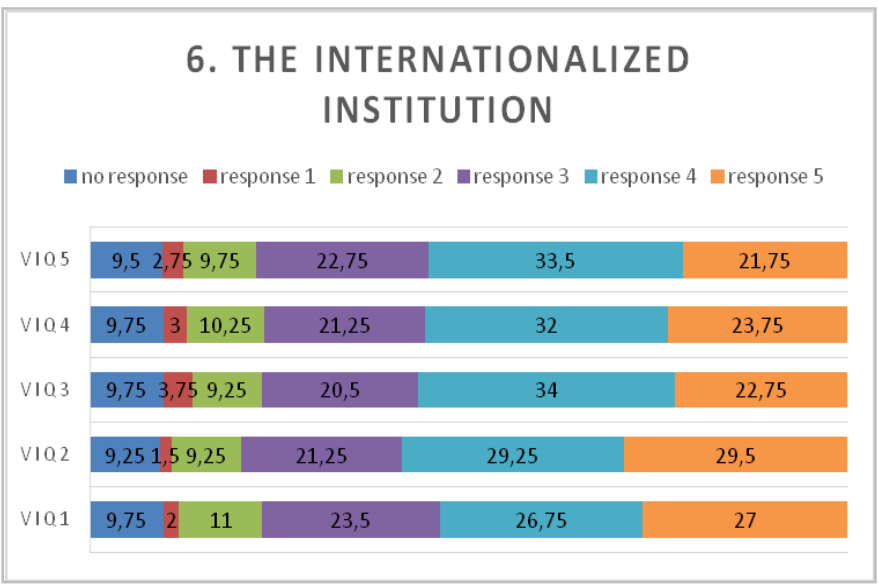

Figure 13. Politehnica University of Timișoara Survey results for Area 6

Source: Taucean, I. M., Strauti, A. G., Tion, M., Roadmap to Entrepreneurial University - Case study, Elsevier Ltd.,

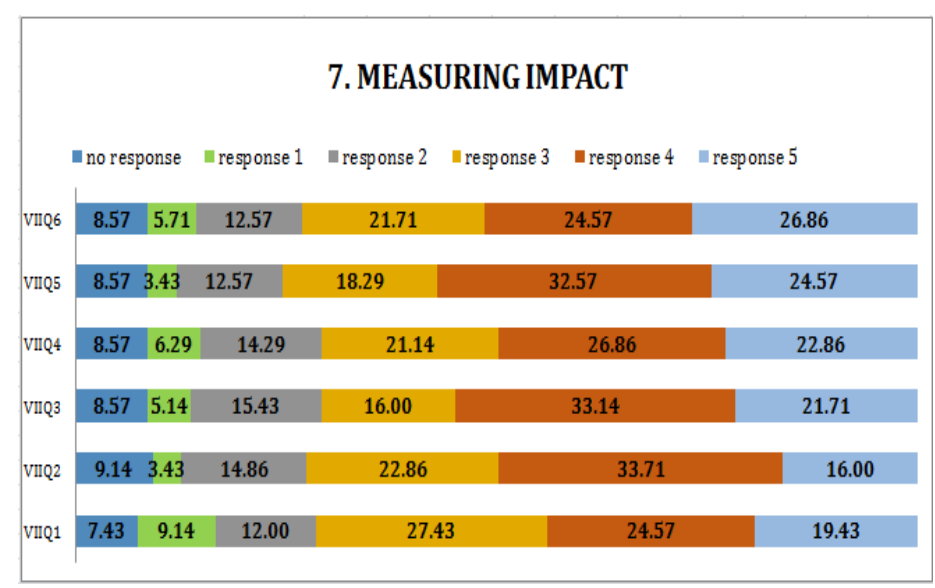

Figure 7. „Ștefan cel Mare” University of SuceavaSurvey results for Area 7

Source: Authors' own research

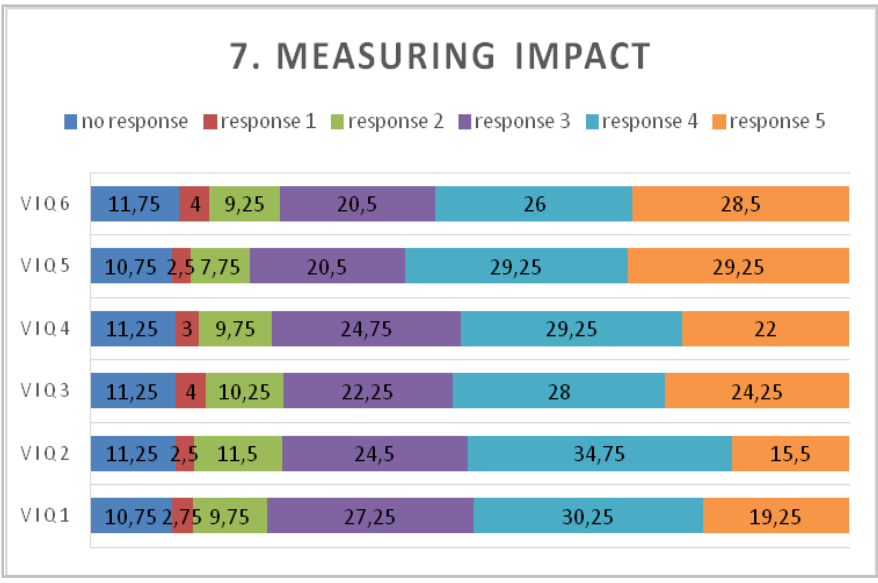

Figure 14. Politehnica University of Timișoara Survey results for Area 7

Source: Taucean, I. M., Strauti, A. G., Tion, M., Roadmap to Entrepreneurial University - Case study, Elsevier Ltd.,

Regarding the results of the questionnaire (figures 1 to 14) at the two universities, i.e. „Ștefan cel Mare” University of Suceava and „Politehnica University of Timișoara on all seven pillars, we highlight the following analysis:

(1) The current situation of both universities is somehow similar; both HEIs are at the beginning of constructing and developing a performing entrepreneurial university among the ones in Romania;

(2) Analyzed universities are in some way different in their characteristic, UPT having mainly technical faculties, such as engineering and USV includes, besides engineering (electrical, mechanical), other specializations like economic sciences, 
educational sciences, law and administrative sciences, philology and other. Despite their divergence in curricula, we argue that HEInnovate is an appropriate tool to assess entrepreneurship and innovation at the institutional level beyond scarce initiatives and activities that are being implemented. Furthermore, once the questionnaire is applied to a variety of stakeholders, we concluded that this assessment is reaching beyond what is known (leadership level of HEIs) and is evaluating the perception level of entrepreneurship and innovation, as well. This is also to show that entrepreneurship and innovation are characteristics to both institutional and individual level and should be developed in HEIs staff, but students too;

(3) Making a comparison of the two universities from Romania with the results of the HEI questionnaire in the other countries of Europe, we can definitely state that in Romania the process of becoming an entrepreneurial university is at its beginning, but on the rise since many of Romanian HEIs have understood that this is nowadays the new role a university should undertake if they aim at achieving greater financial sustainability, improve the level of employability in students and enhance education effectiveness;

(4) In the developed countries of Europe (for example Austria, Germany, Denmark, Finland), entrepreneurship is taught to students from all faculties, through a concentrated portfolio of courses and also have established a network of external lecturers; the courses are based on real-world entrepreneurial study cases, offering also access to "innovation lab" (www.heinnovate.com). That is to prove that Romanian universities barely started to transform from traditional learning institutions to entrepreneurial universities and a series of good practices and implementing successful models represent stimulus for overcoming this infant stage of development.

(5) Since HEInnovate is merely a self-assessment tool of entrepreneurship and innovation in tertiary education institutions, we find that responses to the questionnaire applied in both UPT and USV are not consistent with the vision of the Romanian National Strategy for Tertiary Education for the period 2015-2020. We conclude that this is a major breach between current state of play of Romanian HEIs and the idealistically formulated vision which stipulates that the main objective for development of tertiary education is to be achieved through concentrated efforts in order for Romania to join, by 2030, the European states having advanced economies. According to this vision, by year 2020 (which is next year), the highly performing tertiary education will constitute the drive of economic growth, will contribute to increase of productivity and will promote social inclusion, thus laying the foundation of knowledge based economy. It is a well known fact that Romanian economy has not reached competitiveness and specialists and experts are not being trained in all fields covered by HEIs. Being only at an infant level of development, entrepreneurial universities in Romania are not ready yet to fully employ creativity, innovation and entrepreneurship into the society, thus becoming the main sustaining drive of the economy.

\section{Recommendations}

On the basis of initial gaps identified earlier, we identified some challenges which are intrinsic to the imperative of entrepreneurial university development in Romania. First, we observed that entrepreneurship is traditionally being taught and brought to the attention of the students only through classic entrepreneurship courses (optional or mandatory) and compulsory student practice in local enterprises is of short duration (90 hours for bachelor 
degree and 168 hours for master degree). That is to add to the fact that not all students studying in Romanian HEIs, no matter their specializations are being targeted for entrepreneurial or innovative development. Second, the entrepreneurial or innovative measures are not coherently put into effective action, resulting in inefficient process of planning, organization, implementation and evaluation. Third, we argue that there is still resistance to change in what concerns overcoming traditional educational teaching practices or initiating inter-disciplinary teaching methodologies in order to develop transversal skills in students. The change process requires universities to engage with and win over a wide range of stakeholders, including businesses and own teaching and research staff (Kliewe, 2017).

Based on the statements so far, we propose a set of recommendations for short and long-term within universities in Romania in general and „Stefan cel Mare University of Suceava specifically in order to fill the gaps that we encountered above:

i. Aligning the university vision to the principles of entrepreneurial university based on identification and addressing the systemic gaps;

ii. Developing a cohesive brand for HEIs entrepreneurship and innovation, based on every HEI characteristics. For instance UPT is a powerful and influential technical university, while USV has occupied for several years the first place in Romania when counting the number of scientific patents;

iii. Formally assessing the findings of HEInnovate questionnaire through specific procedures and regular audits to implement corrective actions;

iv. Teaching entrepreneurship and innovation through various interactive learning methods, actively involving students from all faculties and specializations and putting them in the decision-making situation regarding the activity of an innovative enterprise, thus embedding entrepreneurial and innovation skills into the curriculum of all students;

v. Widening students' access to various information materials on entrepreneurship education and innovation, as for example case studies, stories of successful businesses, business plans, guides to setting up a company;

vi. Establish an online platform for entrepreneurship with wide information needed to set up an enterprise, with student applications and other resources that will help the students;

vii. Organizing student competitions on entrepreneurship and innovation issues, involving local businesses as well;

viii. Organizing a "Business Plan" as a bi-annual competition, through the strict formation of teams formed by students from different faculties/specializations;

ix. Strengthening relationships with the local business environment, in order to help staff, students and enterprises engage in institutional and interorganizational mechanism to develop the culture of entrepreneurship and innovation in HEIs area of influence;

$\mathrm{x}$. In cooperation with the enterprises, building business models that subsequently will be applied on the market; 
xi. Strengthening students' access to various mentorship, internship and sponsorship programs in NE region.

The recommendations that were proposed above will help Romanian HEIs to further develop onto the pathway of becoming entrepreneurial universities, to improve adoption of entrepreneurship and innovation skills among students and stakeholders, and to increase the economic growth and competitiveness of the influential regions. We argue that "Ștefan cel Mare" University of Suceava should particularly aim at rapidly implementation of entrepreneurial university concept since Norh East region of Romania is still falling down behind other regions from Romania with regards to private investments, rate of employability or birth of innovative business.

\section{Conclusion}

As a general conclusion of this paper, we state that our research has proven the increasing interest in developing entrepreneurial university concept in Romania, in accordance with European strategies and movements and taking into consideration the imperative need for HEIs transform into more than learning institutions. It is undoubtedly that tertiary education is at its earliest implementation of the concept in our country and national strategy in the field should be harmonized with universities' efforts to become motors for sustainable and competitive economic growth in their willingness and scarce initiatives to develop skills for entrepreneurship and innovation, to create functional mechanism with stakeholders and overcome financial challenges.

The current research is not without limitations in the sense that it compared the results of HEInnovate questionnaire in only two of the existing Romanian universities and it did not identify and evaluate the intentions or even the actual measures undertaken by leadership of these HEIs as to further develop the concept. We do not question that the management teams of HEIs realized the role that HEIs should play in this ever changing economy, but we are reluctant that they will cohesively and coherently succeed in their transformation with no support from governmental policy or financial allocation of resources. Still, information obtained through this research has proven to be valuable in terms of evolution of debate regarding the enhancing roles of universities and progress achieved so far. We argue that this is a solid ground for gaining an entrepreneurial and innovative mindset in both institutions and individuals.

Contributions of the current paper include a set of recommendations for short and long term future based on the actual findings and comparisons of the self-assessment tool represented by HEInnovate questionnaire. These proposed guidelines are meant to offer some direction to the institutional efforts of embedding entrepreneurial university concepts into their mission or vision for future development considering all stakeholders involved: staff, students, business, and government. Beneficial to these changes would be further discussions on the subject since more knowledge means more development of the society. We thus state that focus on entrepreneurship and innovation should cross the barrier of current intentions to future harmonized actions with the aim of enhancing a strong link between academia and economy.

\section{References}

Bercovitz, J., \& Feldmann, M. (2006). Janet Bercovitz 1 Maryann Feldmann 2. Technology, 
175-188. https://doi.org/https://doi.org/10.1016/j.healthplace.2009.10.009

Bledow, R., Frese, M., Anderson, N., Erez, M., \& Farr, J. (2009). A Dialectic Perspective on Innovation: Conflicting Demands, Multiple Pathways, and Ambidexterity. Industrial and Organizational Psychology, 2(03), 305-337. https://doi.org/10.1111/j.17549434.2009.01154.x

Clark, B. R. (1998). Clark, Burton R. Creating Entrepreneurial Universities. Organizational Pathways of Transformation, (C), 180.

Croitoru, A. (2012). Schumpeter, J.A., 1934 (2008), The Theory of Economic Development: An Inquiry into Profits, Capital, Credit, Interest and the Business Cycle, translated from the German by Redvers Opie News Brunswick (U.S.A) and London (U.K.): Transaction Publishers. A re. Journal of Comparative Research in Anthropology and Sociology, 3(2), 137-148. https://doi.org/10.2307/1812657

Davidsson, P. (2004). Researching entrepreneurship. New York: Springer.

Drucker, P. (2001). An excerpt from The Essential Drucker. Retrieved from file:///C:/Users/Cecilia/Downloads/The_Essential_Drucker_The_Best_of_Sixty_Year s_of_Peter_Drucker's_Essential_Writings_on_Management.pdf

Drucker, P. F. (2008). Management: revised edition. New York: HarperCollins.

Dunning, J. H. (2002). Regions, Globalization, and the Knowledge-Based Economy. Retrieved from https://econpapers.repec.org/RePEc:oxp:obooks:9780199250011

Etzkowitz, H. (2004). Evolution of the Entrepreneurial University. International Journal of Technology and Globalization (Vol. 1).

Gibb, A., Haskins, G., Hannon, P., Robertson, I., Gibb, A., Haskins, G., ... Robertson, I. (2012). EULP_-_LEADERS_PAPER_final_dec_19.

Hebert, R., \& Link, A. (1989). In Search of the Meaning of Entrepreneurship. Small Business Economics (Vol. 1). https://doi.org/10.1007/BF00389915

Junior Achievement Romania (2016), Proiect “Universitatea Antreprenorială”. Available at: https://www.jaromania.org/proiecte/proiect-universitatea-antreprenoriala

Kliewe, T. (2017). Entrepreneurial and engaged university accreditation.

Lazzeretti, L., \& Tavoletti, E. (2005). Higher education excellence and local economic development: The case of the entrepreneurial University of Twente. European Planning Studies, 13(3), 475-493. https://doi.org/10.1080/09654310500089779

Lee, S. H., Peng, M. W., \& Song, S. (2013). Governments, entrepreneurs, and positive externalities: A real options perspective. European Management Journal, 31(4), 333347.

Levy, F., \& Murnane, R. (2005). How Computerized Work and Globalization Shape Human Skill Demands. https://doi.org/10.1525/california/9780520254343.003.0008

Nooteboom, B., \& Went, R. (2008). Innovation and Organisation. Microfoundations for Innovation Policy.

Perkins, D. (1999). The Many Faces of Constructivism. Educational Leadership (Vol. 57).

Rotherham, A. J., \& Willingham, D. T. (2010). "21st-Century" skills. American Educator, 17, 17-20.

Salamzadeh, A., Salamzadeh, Y., \& Daraei, M. (2011). Toward a systematic framework for an entrepreneurial university: a study in Iranian context with an IPOO model.

Stephan, U., \& Uhlaner, L. M. (2010). Performance-based vs socially supportive culture: A cross-national study of descriptive norms and entrepreneurship. Journal of 
International Business Studies, 41(8), 1347-1364.

https://doi.org/10.1057/jibs.2010.14

Stevenson, H. H., \& Jarillo, J. C. (1990). A paradigm of entrepreneurship: Entrepreneurial management. Strategic Management Journal, 11, 17-27.

Taucean, I. M., Strauti, A. G., \& Tion, M. (2018). Roadmap to Entrepreneurial University Case study. Procedia -Social and Behavioral Sciences, 238, 582-589. https://doi.org/10.1016/j.sbspro.2018.04.038

UNESCO (2005), From the Information Society to Knowledge Societies. UNESCO Publishing, Paris, France.

Westwood, R., \& Low, D. R. (2003). The multicultural muse: Culture, creativity and innovation. International Journal of Cross Cultural Management, 3(2), 235-259. https://doi.org/10.1177/14705958030032006

Wilson, K. E., Vyakarnam, S., Volkmann, C., Mariotti, S., \& Rabuzzi, D. (2009). Educating the Next Wave of Entrepreneurs: Unlocking Entrepreneurial Capabilities to Meet the Global Challenges of the 21st Century. Ssrn, (April). https://doi.org/10.2139/ssrn.1396704

https://heinnovate.eu/en/resources. Accessed on 29.01.2018 